\title{
Elevation, volume and terminus changes of nine glaciers in North America
}

\author{
J. J. Sapiano, W. D. Harrison, K. A. Echelmeyer \\ Geophysical Institute, University of Alaska-Fairbanks, Fairbanks, Alaska 99775, U.S.A.
}

\begin{abstract}
Nine glaciers in Alaska and Washington, U.S.A., originally mapped as part of the International Geophysical Year (IGY) in 1957-58, were re-mapped between 1993 and 1996, eight using airborne surface elevation profiling and the ninth using ground-based kinematic global positioning system methods. Elevation, volume and terminus changes were determined for the approximately 38 year period between the IGY mapping and the profiling. All nine glaciers showed substantial thinning at lower elevations; seven of the nine thickened at higher elevations. None of the glaciers had a significant net volume increase; two had close to zero change, and the others had a decrease. For the eight glaciers for which we could obtain quantitative information, the mean thickness change was $-10 \mathrm{~m}$ with a large scatter, $8 \mathrm{~m}$ standard deviation. The volume and terminus changes had no clear geographic pattern, and no simple relationship between volume change and terminus advance or retreat was identified. The largest error in the estimated volume changes is due to map errors.
\end{abstract}

\section{INTRODUCTION}

It is important to monitor small glaciers and ice caps because they are sensitive indicators of local climate and because they may have a significant effect on sea level (e.g. Meier, 1984, 1990; Oerlemans and Fortuin, 1992; Schwitter and Raymond, 1993). Mass balance is often determined by traditional stake methods once or twice a year. However, in many parts of the world, including North America, these types of measurements are sparse (e.g. Haeberli and Hoelzle, 1993), and it is attractive to apply other techniques. One such technique is the "topographic method", in which the average annual mass balance is determined over a period of several years by the comparison of two topographic maps. The foundation for such a topographic comparison was established in North America with the preparation of a set of photogrammetric maps in 1957-58 as part of the International Geophysical Year (IGY) (American Geographical Society, 1960). Nine small glaciers, whose locations are shown in Figure 1, were chosen to be representative of different climatic regions in Alaska and Washington, U.S.A. A map of each glacier was produced at a scale of $1: 10000$ and a contour interval of $5 \mathrm{~m}$.

Expense and logistical problems, especially those arising from the necessity of establishing ground control in remote areas, have made it difficult to re-map the IGY glaciers. Recent detailed maps of only two of the nine glaciers have been published: Lemon Creek in 1989 (Marcus and others, 1995) and West Gulkana in 1986 (Marcus and Reynolds, 1988). McCall Glacier has also been the subject of ongoing research by Rabus and others (1995), including complete resurveying of the surface in the 1990s (Rabus and Echelmeyer, in press).

The cartographer for most of the IGY maps noted that a method of mapping these glaciers without establishing ground control would result in a great saving of time and money (Case, 1959). This can be done now by airborne surface-elevation profiling. We developed a profiling system which mounts in a light aircraft capable of flying in the narrow mountain valleys typical of these small glaciers (Echelmeyer and others, 1996), and used it to map eight of the nine glaciers between 1993 and 1996. We profiled the ninth glacier using ground-based survey methods.

The profile data collected by these methods consist of elevations measured along one or more longitudinal tracks down a glacier. Although the coverage is limited, the accuracy is one or two orders of magnitude better than that commonly obtained in photogrammetry. We have developed a method that extrapolates these profile data to approximate the complete topography of a glacier at the time of profiling, thereby permitting the calculation of volume change.

Here we present our observations of the recent glacier elevation profiles. The methods of profile and map comparison are outlined, and surface-elevation changes are calculated. The quality of the IGY maps is then discussed. Glacier volume and terminus changes are calculated using these maps and the profile data, and the errors in the volume change are estimated. The observed changes are considered in a regional context, and some of the connections with glacier geometry, climate, sea level and glacier dynamics are discussed.

\section{OBSERVATIONS}

\section{The airborne elevation-profiling system}

The elevation-profiling system consists of a pulsed infrared laser ranger, a gyroscope and a compass, all rigidly mounted on a single platform in the rear of the aircraft. The ranger measures the distance from the aircraft to the ice surface, and the gyro and compass together determine the orientation of the ranger. The position of the aircraft is 

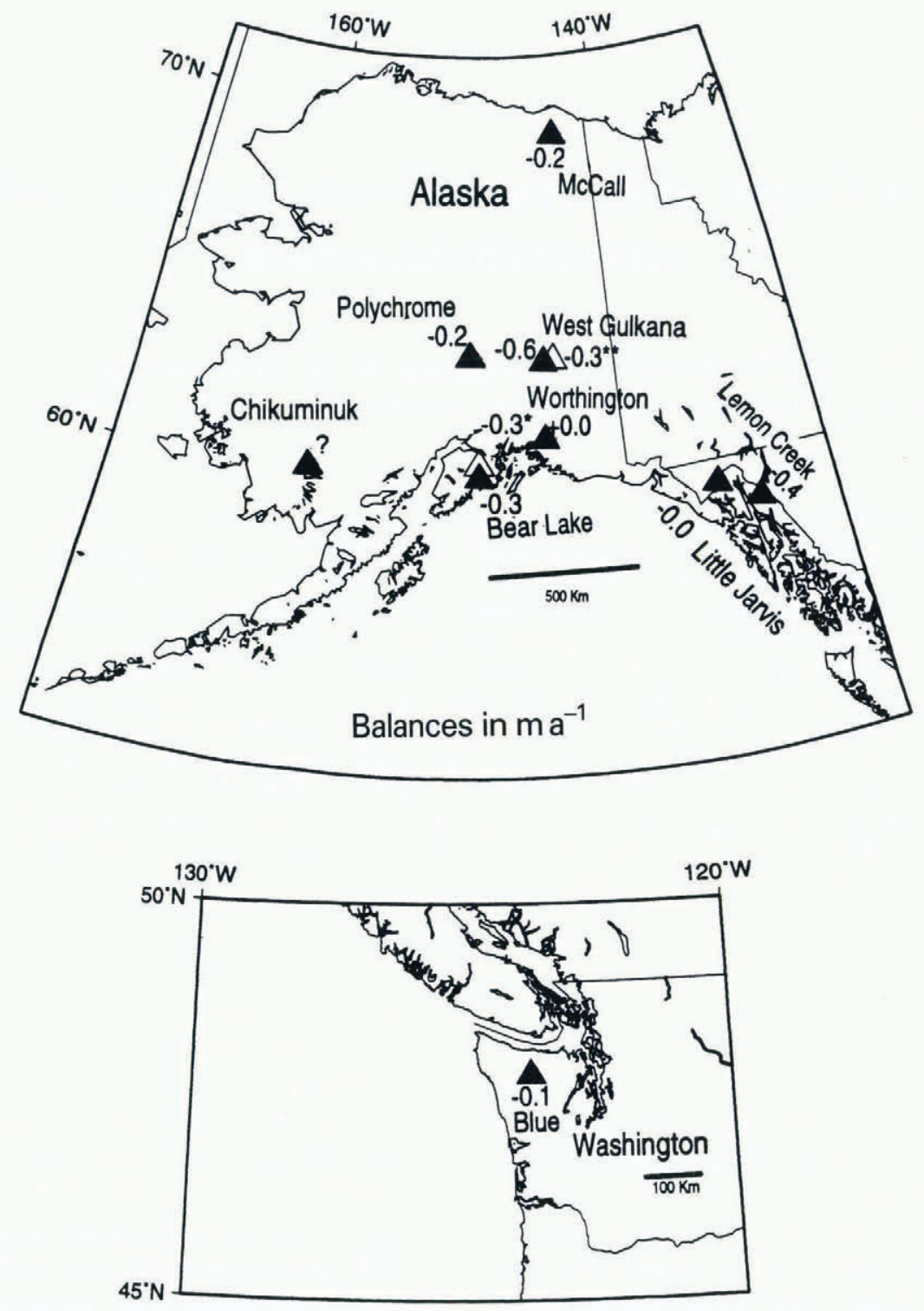

Fig. 1. Location maps for the nine IGY glaciers. Numbers are average annual balances $\left(\left\langle b_{\mathrm{a}}\right\rangle\right.$ in Table 5). Also included as open triangles are Wolverine Glacier (*) and Gulkana Glacier (**) from 1966 to 1995 (personal communication from USGS, 1996).

determined using continuous kinematic global positioning system (GPS) techniques. Data from the separate components of the system are combined to give the elevation and horizontal coordinates of discrete points on the surface of the glacier. Sampling at $25 \mathrm{~Hz}$ yields elevations and positions along the surface about every $1.2 \mathrm{~m}$ on the profile. The accuracy of the elevations has been shown to be typically $0.3 \mathrm{~m}$ or better, although it can be worse over steep surfaces because uncertainty in the orientation of the ranger causes appreciable uncertainty in the point of intersection with the surface. Further details are given in Echelmeyer and others (1996).

These data are presented in a Universal Transverse Mercator (UTM) projection, with horizontal coordinates referenced to the World Geodetic System of 1984 (WGS84). Surface elevations are given as height in meters above the WGS84 ellipsoid (here designated "HAE"). These coordinates are not referenced to the same datum as most maps, and care must be taken when comparing the two.

\section{Elevation profiles}

Table 1 gives a description of each glacier and a summary of the data collected. As indicated in the table, several profiles were flown along each glacier in order to obtain more complete spatial coverage. Figure 2a shows an example of these profiles along Bear Lake Glacier. The ground tracks of these profiles, which are the loci of points where the ranger beam intersects the ice surface, are superimposed on the glacier topography as defined by the IGY map. (The map contours are given in approximate elevation above mean sea level.) Figure 3 shows the elevations measured along one of these profiles, together with the map elevation (HAE) at each contour. There are some gaps in the data because of limitations in the ranger performance over rough and steep terrain (Echelmeyer and others, 1996). Figure 2b-i show the ground tracks of the profiles on each of the other glaciers. The profiles on Polychrome were obtained with groundbased kinematic GPS methods.

\section{Map control}

Most of the IGY maps were referenced to local control networks that were not tied accurately into any absolute coordinate system, horizontal or vertical. This prevented a direct comparison of the maps with our profile data. It was therefore necessary to tie the maps into the WGS84 reference system by resurveying at least two of the IGY control 


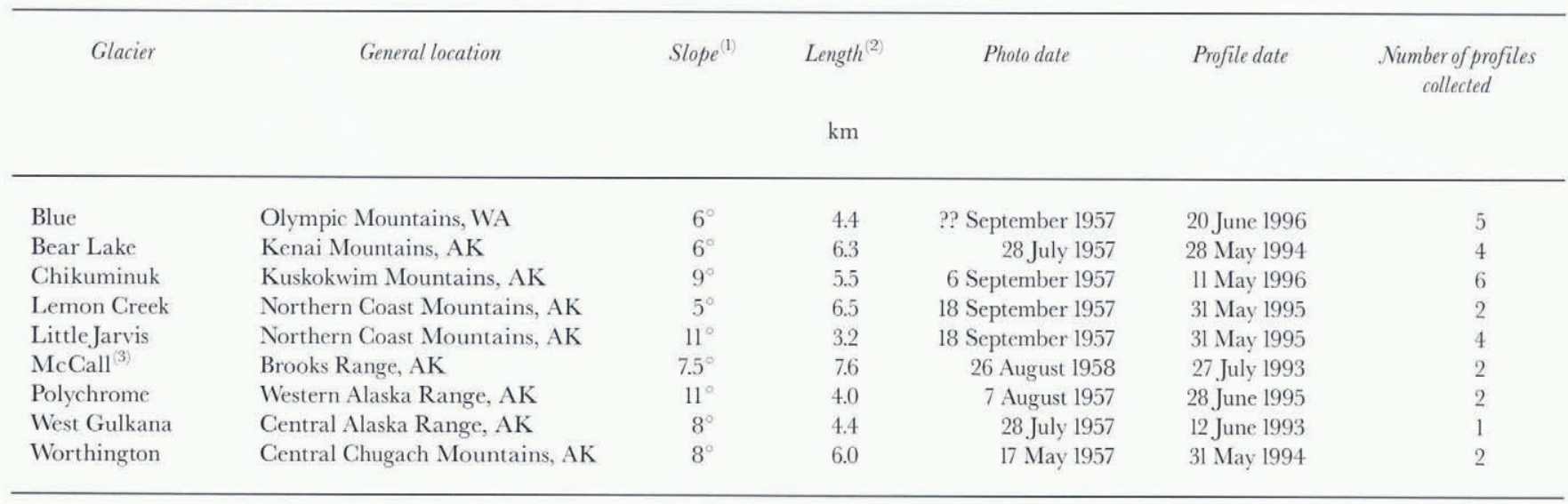

\footnotetext{
1) Average surface slope.

(2) Length of glacier on date of map photographs.

(3) Data from Rabus and others (1995).
}

points used for each map. We used geodetic GPS methods to obtain coordinates to an accuracy of better than $0.2 \mathrm{~m}$. Figure $2 \mathrm{a}-\mathrm{i}$ show the positions of these points for each glacier. The names listed, when available, are those of the IGY survey. Otherwise, the points are assigned a number which corresponds to point elevations printed on the maps. The exact locations of the IGYcontrol points were sometimes ambiguous in the field, even though there was evidence of a cairn or other marker at each site that we surveyed. In some cases, more than the necessary two points were surveyed, providing a check of our coordinate transformation procedure. The coordinates of all control points were determined with respect to nearby U.S. Geological Survey (USGS) benchmarks, most of which were first-order points. The coordinates of the IGY control points which we surveyed and those of the USGS benchmarks used as reference are given in Sapiano (1996).

\section{Snow depths}

The comparison of our elevation data with those from the maps is further complicated because the two datasets were often collected at different times of year (Table 1). To correct for this difference, whenever possible we measured, at the time of profiling, a longitudinal profile of snow depth along each glacier by probing to the previous summer surface. Substantial errors may be expected where the snow is deep and the summer surface difficult to identify. The measured snow depths were extrapolated over the entire surface area to obtain the average snow thickness. Where we could not measure snow depth directly, various estimation methods were used. The methods and results are summarized in Table 2.

\section{ABSOLUTE COORDINATES FOR THE IGY MAPS}

The first step in the comparison of the map and profile elevations was to transform the local coordinates used on the IGY maps to the WGS84-referenced coordinates used for the profile data. Both a horizontal and a vertical adjustment were required.

The horizontal coordinates were determined by placing each IGY map on a digitizing table and measuring the horizontal positions of two of the control points in the coordinate system defined by the table. These coordinates, together with the corresponding WGS84-referenced coordinates determined by our ground survey (stated in UTM), supplied the information necessary to determine the parameters to scale, translate and rotate the digitized maps to the WGS84 reference system (see Sapiano, 1996, for details).

The vertical coordinates (HAE) were determined by comparing our surveyed elevations of the control points with those of the IGY survey, thereby establishing the appropriate mean vertical offset for a particular glacier. We found the IGYcontrol to be internally consistent for most of the maps. Because it was not required to tie either of the elevations (map or profile) to sea level, and because the glaciers were relatively small, the vertical transformation was independent of any geoid model and its associated errors.

The coordinates of a map point determined by these methods suffer from two sources of uncertainty. A minor problem is our digitization procedure, which introduced a horizontal random error of about $5 \mathrm{~m}$; the systematic error

Table 2. Area-average snow depth on the glaciers near the time of profiling

\begin{tabular}{cc}
\hline Glacier & Snow depth \\
$\mathrm{m}$
\end{tabular}

\begin{tabular}{|c|c|c|}
\hline Blue & $5.3 \pm 1.5$ & $\begin{array}{l}\text { Calculated from snow depths collected at } \\
\text { time of profile (personal communication } \\
\text { from } \mathrm{H} \text {. Conway) }\end{array}$ \\
\hline Bear Lake & $2.8 \pm 1.0$ & $\begin{array}{l}\text { Calculated from snow depths collected in } \\
1996\end{array}$ \\
\hline Chikuminuk & $4.2 \pm($ small $)$ & $\begin{array}{l}\text { Calculated from snow depths collected at } \\
\text { time of profile }\end{array}$ \\
\hline Lemon Creek & $2.0 \pm 1.5$ & $\begin{array}{l}\text { Estimated from snow depths collected late in } \\
1996\end{array}$ \\
\hline Little Jarvis & $1.5 \pm 2.0$ & $\begin{array}{l}\text { Estimated from visual observations at time } \\
\text { of profile }\end{array}$ \\
\hline McCall & $\approx 0$ & $\begin{array}{l}\text { Map photographs taken close to time of } \\
\text { profile }\end{array}$ \\
\hline Polychrome & $0.2 \pm($ small $)$ & $\begin{array}{l}\text { Estimated from visual observations at time } \\
\text { of profile }\end{array}$ \\
\hline West Gulkana & $2.3 \pm($ small $)$ & $\begin{array}{l}\text { Estimated from } 1987 \text { snow-depth obser- } \\
\text { vations and } 1993 \text { snow-depth data from } \\
\text { nearby Gulkana Glacier }{ }^{1}\end{array}$ \\
\hline Worthington & - & $\begin{array}{l}\text { Map photograph taken close to time of } \\
\text { profile }\end{array}$ \\
\hline
\end{tabular}

(1) Snow-depth data from March and Trabant (1996). 

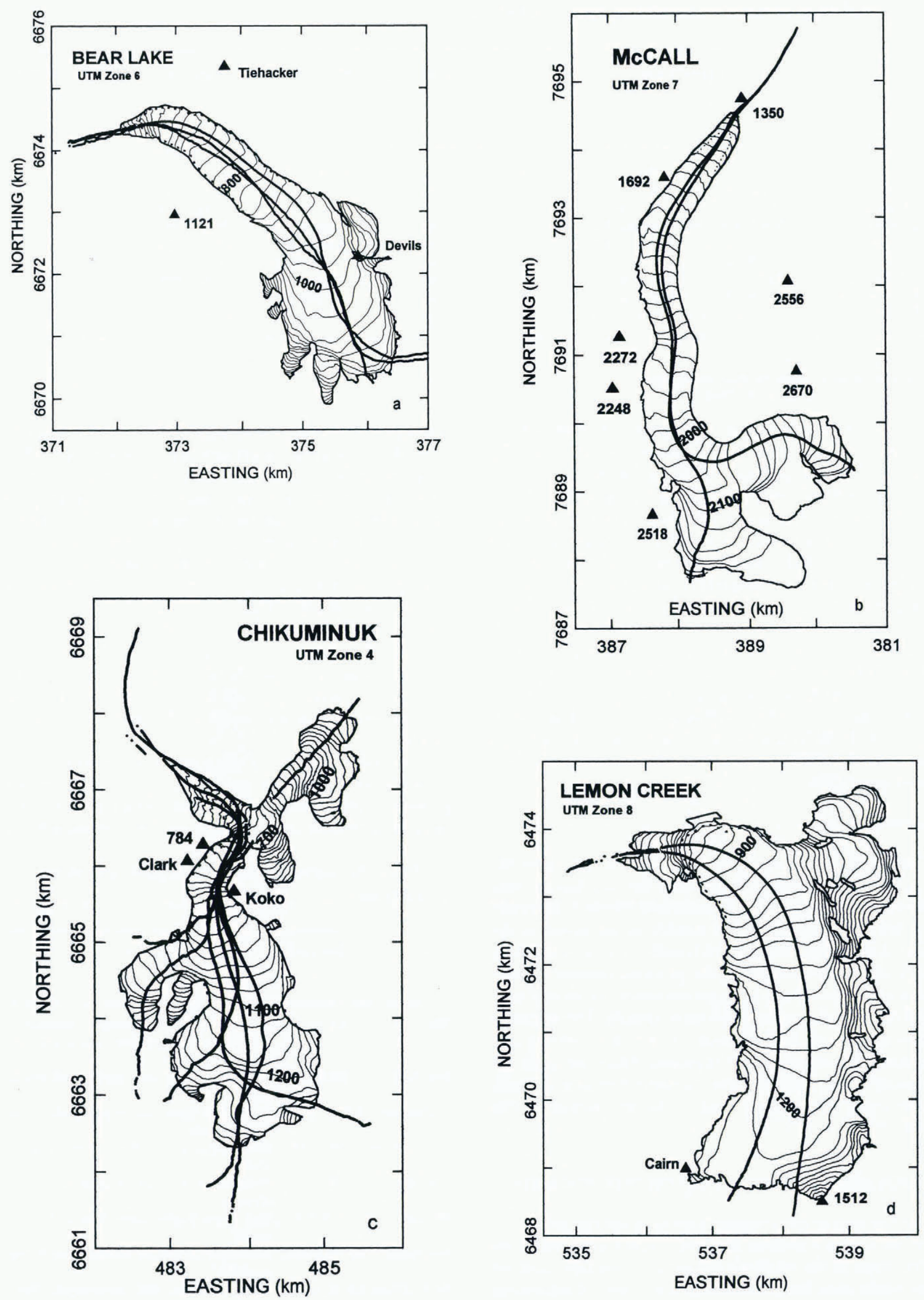

Fig. 2. IGY glacier topography with the 1990s profile ground tracks. Elevations are those shown on the IGY map, and the contour interval is $25 \mathrm{~m}$. The IGY and 1990s boundaries are shown by the solid and dashed lines, respectively. IGY control points are shown by the solid triangles. (a) Bear Lake, (b) McCall, (c) Chikuminuk, (d) Lemon Creek, (e) Little Farvis, (f) Blue, ( $g$ ) Polychrome, (h) West Gulkana, (i) Worthington. 

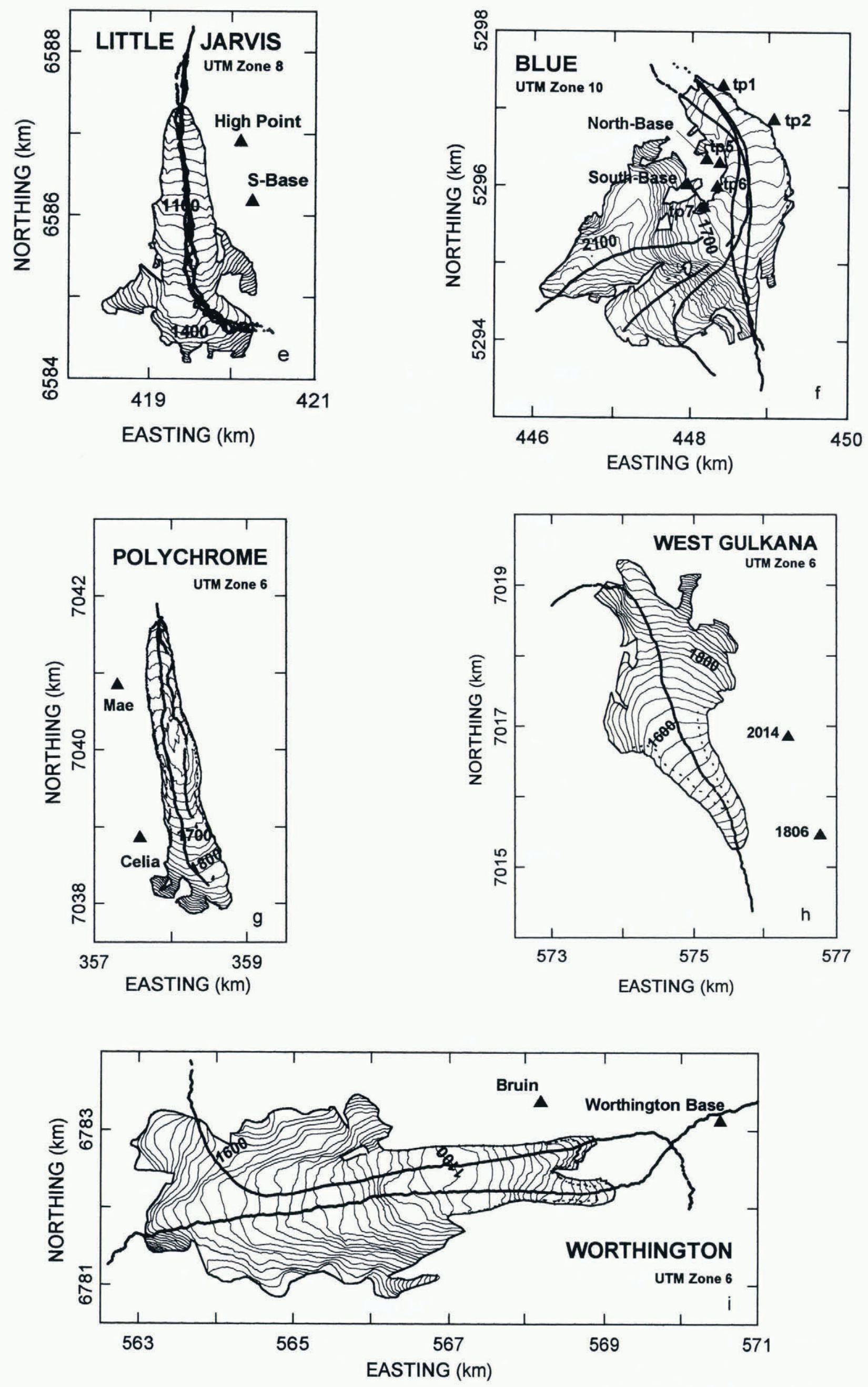


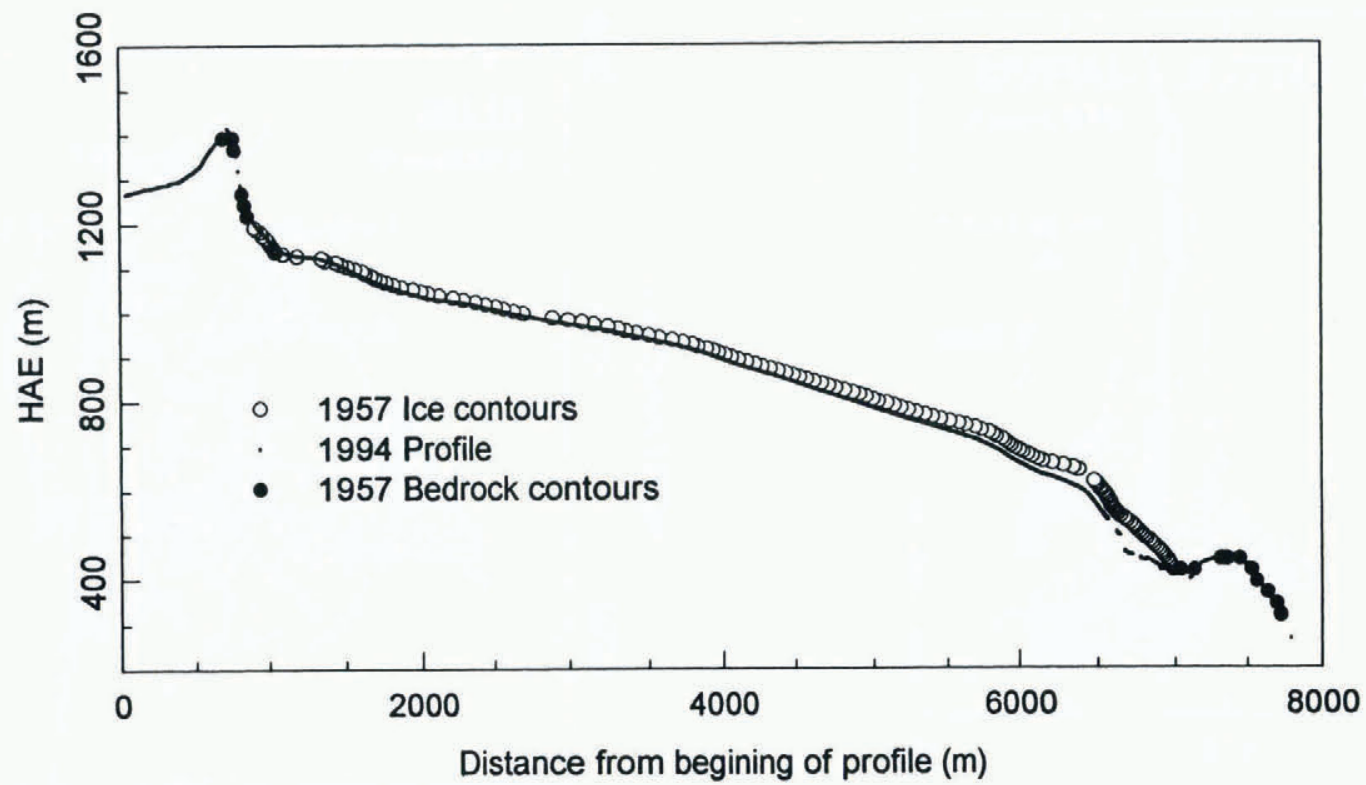

Fig. 3. Bear Lake Glacier profile and map elevations along one of the profiles shown in Figure 2. Elevations are height above the WGS84 ellipsoid (HAE in meters). This profile was extended well beyond the glacier boundary to measure the proglacial area. There are some gaps in the elevation-profile data where the terrain is steep and over the rough moraine near the terminus.

is relatively small. A much more serious problem, which could lead to major systematic errors, is the possible misidentification of an IGY map control point in the field. However, such errors seem to be ruled out by the checks which we made by profiling over mapped bedrock areas, as discussed below.

\section{SURFACE-ELEVATION CHANGES}

We determined the surface-elevation changes between the time of map construction and that of elevation profiling at points where the ground track of the profile intersected the map contours (Echelmeyer and others, 1996). Software developed by B. Rabus (personal communication, 1995) was used to find these intersection points. Elevation changes at the contour intersections on Bear Lake Glacier are shown in Figure 4 for the three profiles flown, along with their average values. These changes are defined as profile elevation minus map elevation, and thus negative values of elevation change indicate thinning since the IGY. Intersection points on bedrock are shown with small filled symbols. It was not always feasible to measure elevation changes in the highest glacierized regions; these were estimated by extrapolation and are indicated by large filled circles. Average elevation changes for the remaining eight glaciers, including these extrapolated changes, are shown in Figure 5. The average elevation change shown is the mean elevation change over all the profiles on the glacier that intersect a given con-

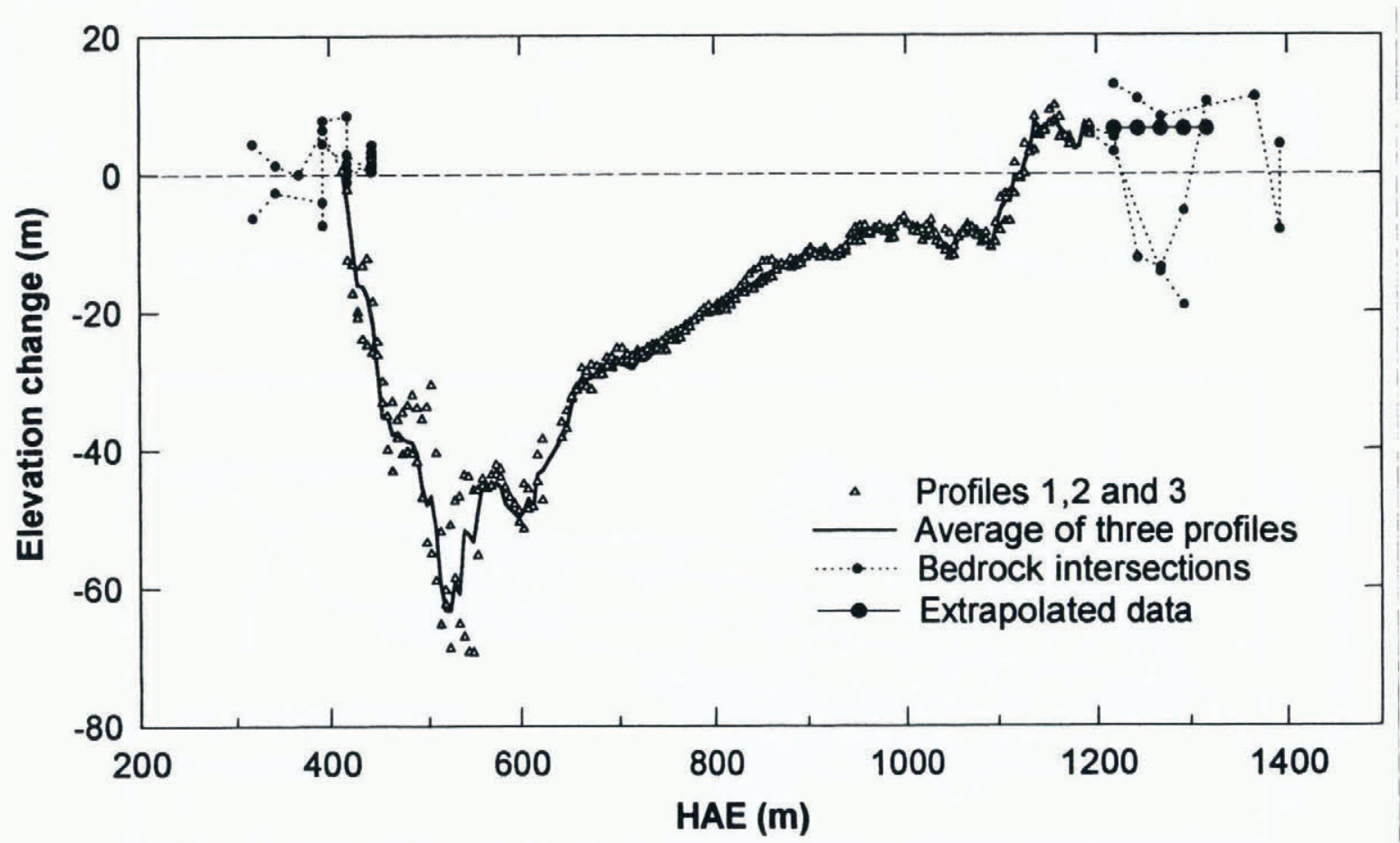

Fig. 4. Bear Lake Glacier elevation changes $(m)$ us elevation (HAE) for the three different profiles. The average elevation change is shown with a solid line. Points where the profile crosses bedrock are indicated with small solid symbols. The large solid symbols indicate extrapolated data points on the glacier. 

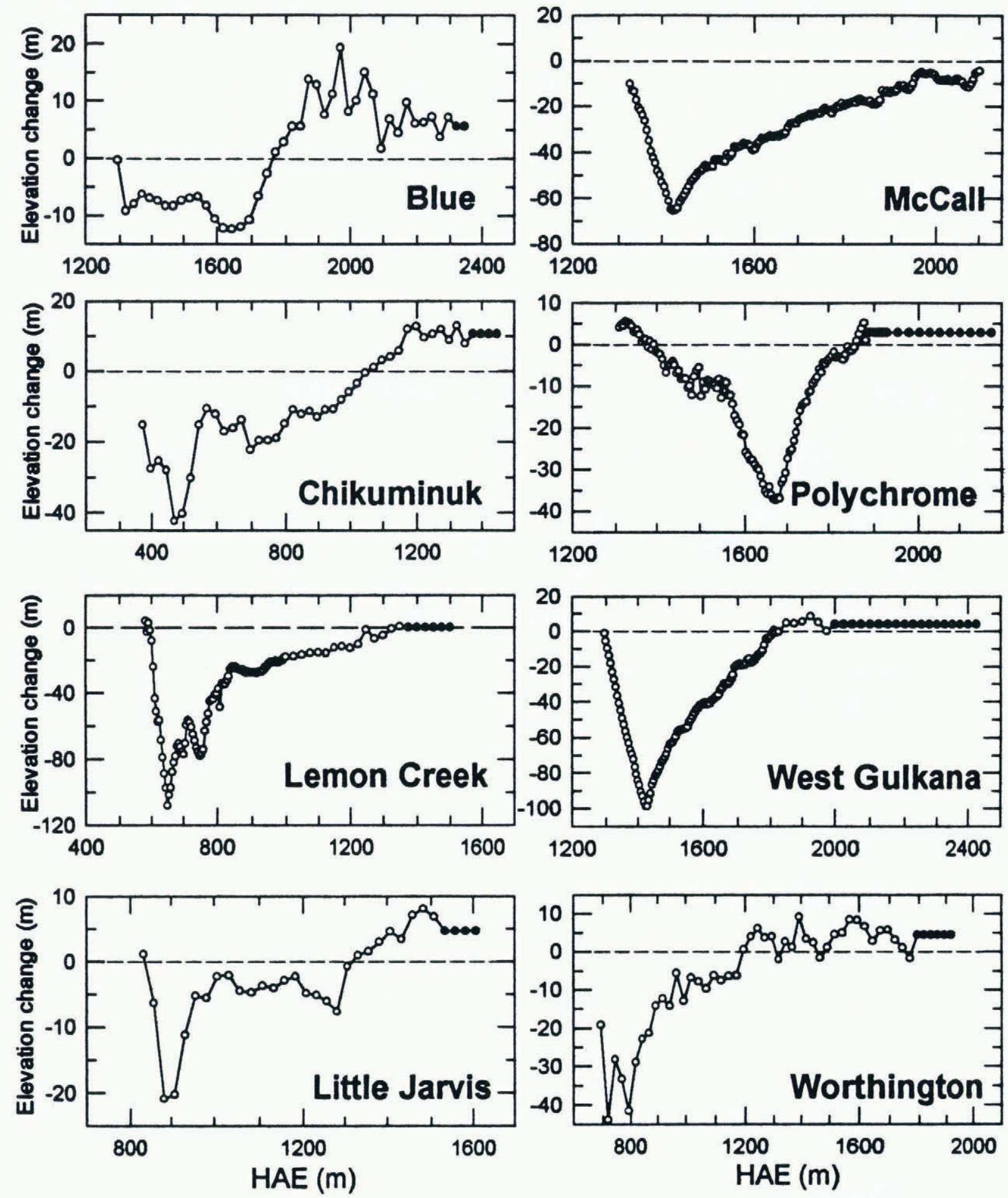

Fig. 5. Average elevation change ( $m$ ) vs elevation (HAE). All IGY glaciers are shown except Bear Lake (see Fig. 4). The solid symbols indicate extrapolated data points.

tour. All elevation-change curves show significant thinning, with a maximum of $110 \mathrm{~m}$ in the lower regions of some glaciers. Seven of the nine glaciers showed some thickening at higher elevations. Each of the curves shows sharply reduced thinning at the IGY position of the terminus; this is because the thin ice that existed there was removed completely as the terminus retreated, leaving unchanging "bedrock" that was later profiled. Glaciers that underwent significant retreat, such as West Gulkana, display this effect more strongly than those that did not retreat much, such as Worthington Glacier. The upper part of the elevation change profile for McCall Glacier has been omitted in Figure 5 because of large IGY map errors; complete profiles were compared to a 1956 USGS map (Rabus, 1997).
In order to calculate volume and an area-average thickness change, one must decide what will be included within the boundaries of a glacier. Our choices are shown in Figure $2 \mathrm{a}-\mathrm{i}$. In some cases, the boundaries include ice slopes which contribute water, but not ice, to the glacier valley (e.g. Worthington and Blue Glaciers). In the case of Blue Glacier, a region known as "Snow Dome" was included, even though part of it feeds another nearby glacier. The distribution of area with elevation within these boundaries was needed for each glacier. We determined the area contained between the contours of the IGY maps by using the digitized contour data and an area calculation routine developed by B. Rabus (personal communication, 1995). A temporal average of the area within each elevation interval was calculated by taking 
the mean of the IGYarea and the 1990s area; the latter was determined as part of the map-construction methods described below. Curves of average area vs elevation for eight of the glaciers are shown in Figure 6. The curve for McCall Glacier is not shown, because of the large IGY map errors; a curve based on the USGS map is given by Rabus (1997).

\section{MAP QUALITY AND ERRORS IN ELEVATION CHANGE}

Several factors need to be considered in estimating errors in elevation change: the accuracy of the profiler, the accuracy of the maps (including our determination of map control) and the accuracy of our comparison of profile and map elevations. The error in the elevation profiles is too small to affect the estimated elevation changes significantly. The error in our methods for comparing map and profile elevations is significant (see Sapiano, 1996, for details), but the main factor is the accuracy of the maps. The tests described below give a measure of the combined effect of these errors.

The vertical accuracy of the nine IGY maps is stated to be one half a contour interval, or $2.5 \mathrm{~m}$ (Case, 1959; Ameri-
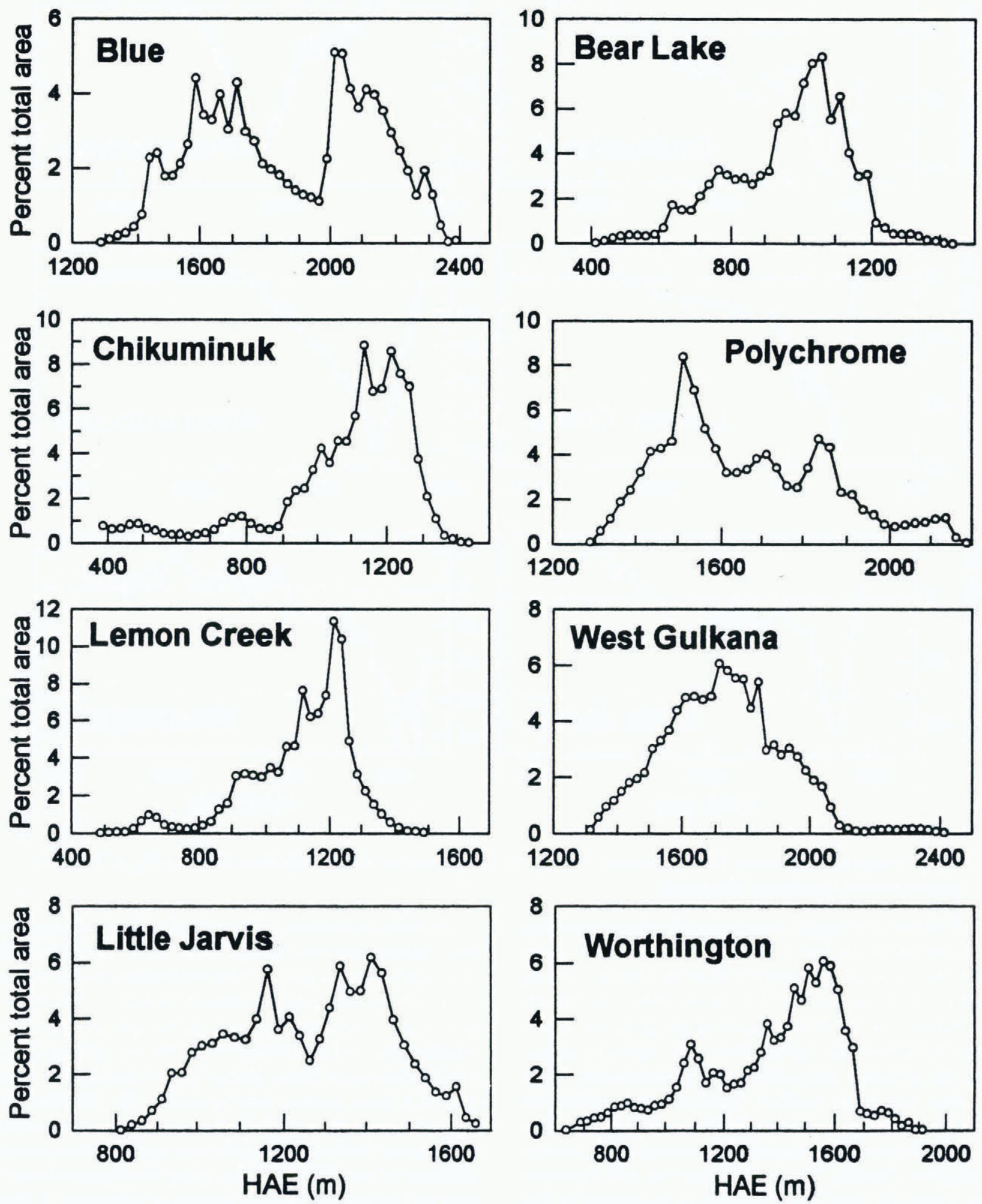

Fig. 6. Area distribution expressed as percentage of total average area per 25 m elevation interval vs elevation (HAE). The average areas are calculated from the areas shown in Table 5. 
can Geographical Society, 1960). However, several maps include some dashed contours, which indicate reduced accuracy in regions of poor photographic contrast. We inspected the available photographs used for the IGY mapping, and found no obvious problems in addition to those indicated by these dashed contour lines. However, the maps of Chikuminuk and McCall Glaciers have substantial systematic errors, as discussed below.

Information on the magnitude of random and systematic errors in the maps and those inherent in our methods of comparison was obtained by examining apparent elevation changes where the profiles intersected contour lines on unglacierized terrain ("bedrock", indicated by the small filled circles in Figure 4). Because of the large vertical errors that can be introduced in the steep areas found at the heads of many glaciers, only the bedrock intersections in the proglacial areas were used to judge map quality (except on Chikuminuk Glacier, as noted below). Unfortunately, some of the proglacial areas are steep as well. The number of such intersections on each map, along with the mean elevation difference, the standard deviation about this mean and the standard error of the mean for these bedrock contour intersections, are listed in Table 3.

The standard deviation about the mean provides an estimate of the random errors in the map-profile comparison. The average of these standard deviations among the different glaciers is about $5-6 \mathrm{~m}$. At face value, this is a measure of the random errors in the contours and in our digitizing procedures. However, much of the bedrock was so steep that the values in Table 3 probably tend to overestimate the error. This is borne out by inspection of the elevation-change data for individual profiles (not shown), which, with some exceptions, tend to be smooth at better than $5 \mathrm{~m}$. As a conservative estimate, we therefore adopt a value of $5 \mathrm{~m}$ for the random error for all glaciers except Blue Glacier (Table 4). This value is equal to one contour interval, or twice that originally proposed.

A check on possible systematic errors introduced by our map-control procedures is given by the mean difference and the standard error of the mean in Table 3 . When the standard

Table 3. Differences between profiled and IGY map elevations on bedrock in proglacial areas (except on Chikuminuk Glacier, as noted in text). Mean difference is profile minus (corrected) mapelevations

\section{Glacier}

$$
\begin{aligned}
& \text { Number of bed- } \\
& \text { rock contours }
\end{aligned}
$$

\section{Mean Standard devi- Standard error difference ation about mean of mean}

$\mathrm{m} \quad \mathrm{m} \quad \mathrm{m}$

$\begin{array}{lrrrl}\text { Blue } & 12 & -3.7 & 10.8 & 3.1 \\ \begin{array}{l}\text { Bear Lake } \\ \text { Chikuminuk, }\end{array} & 24 & 1.5 & 4.0 & 0.8 \\ \quad \text { east branch } & 4 & 28.5 & 5.7 & 2.8 \\ \begin{array}{l}\text { Chikuminuk, } \\ \quad \text { west branch }\end{array} & 8 & -11.1 & 7.0 & 2.5 \\ \text { Lemon Creek } & 6 & -2.1 & 8.4 & 3.4 \\ \text { Little Jarvis } & 4 & 0.3 & 5.9 & 2.9 \\ \text { McCall } & & -10.8 & 7.6 & 2.7 \\ \text { Polychrome } & 8 & - & - & - \\ \text { West Gulkana } & 7 & -1.3 & 1.0 & 0.4 \\ \text { Worthington } & 3 & -3.0 & 0.3 & 0.2\end{array}$

(1) Data from Rabus and others (1995).
Table 4. Summary of errors in elevation change

\begin{tabular}{lccc}
\hline & $\begin{array}{c}\text { Random errors } \\
\text { Mapand digitization } \\
\text { errors }\end{array}$ & $\begin{array}{c}\text { Systematic errors } \\
\text { Detected from bed- } \\
\text { rock intersections }\end{array}$ & $\begin{array}{c}\text { Contour-drawing } \\
\text { error }\end{array}$ \\
& $\mathrm{m}$ & $\mathrm{m}$ & $\mathrm{m}$ \\
\hline Blue & 8 & 1 & 1 \\
Bear Lake & 5 & 1 & 2 \\
Chikuminuk & 5 & 11 & large \\
Lemon Creek & 5 & 1 & 1 \\
LittleJarvis & 5 & 1 & 1 \\
McCall & 5 & large & large \\
Polychrome & 5 & 1 & 1 \\
West Gulkana & 5 & 1 & 1 \\
Worthington & 5 & $2 ?$ & 3 \\
& & & \\
\hline
\end{tabular}

error of the mean is less than the mean difference, there may be an error in the control and therefore a systematic error in map elevation. If Chikuminuk, McCall and Worthington Glaciers are excluded, these errors would appear to be about $1 \mathrm{~m}$. Finally, there is the possibility of a systematic error in the contours drawn in the glacierized areas, especially above the snowline when the photographic contrast was poor and the contours dashed. Photogrammetrically, contours tend to "float" upward in such cases (personal communication from M.E. Southern, 1984). The magnitude of these errors is difficult to estimate; the values listed in Table 4 are our best guesses. We assign larger values to maps with dashed contours. Since this is an estimate of the systematic error in contour drawing, in principle it applies to an entire glacier. If we had treated accumulation and ablation areas separately, the error would have been smaller in the latter, because the photographic contrast there was usually good.

The overall quality of the different maps varies. Based on the errors shown in Tables 3 and 4, and our examination of the mapping photography, we can make the following remarks:

Bear Lake, Lemon Creek, Little Jarvis and West Gulkana Glaciers: These maps appear to have an accuracy of about $5 \mathrm{~m}$, except possibly in the accumulation area of Bear Lake Glacier where there are some dashed contours. There is no apparent systematic offset (relative to the control points) in any of these maps.

Blue Glacier: The mapping photographs appear to be excellent and show minimal snow cover, but the random error based on the bedrock contours appears to be relatively large $(11 \mathrm{~m})$. However, the proglacial bedrock is complex and quite steep. The scatter in the elevationchange curve (Fig. 5) for Blue Glacier is about $\pm 5 \mathrm{~m}$. Based on these two values, we assign a value of $\pm 8 \mathrm{~m}$ for the random error in the contours of this glacier. There are no dashed contours, and therefore only a small systematic error is assigned. It should also be noted that Davey (1962) states that the 1957 map is of excellent quality, with a vertical accuracy of $1 \mathrm{~m}$. This makes our estimate quite conservative.

Chikuminuk Glacier: This glacier consists of two main branches (Fig. 2c), with a common terminus. In the proglacial region the bedrock intersections show no significant systematic offset. However, for this glacier only, the values listed in Table 3 are those for the upper bedrock regions of the two branches (mostly high-elevation 
passes), and these both show large vertical offsets that are in opposite directions. This is probably due to problems with the surveying of the photogrammetric control during the IGY field program. At that time, theodolite surveys were carried out from only two control points, and they were spaced along a short $(150 \mathrm{~m})$ baseline that proved inadequate. The locations of other points needed for photogrammetric control were determined by intersection from these two control points. The geometry of these intersections was poor, and thus the positions of the photo-control points were subject to significant errors. This was especially true in the east branch, where the intersection angle was quite small. Moreover, our measurement of one of the distances that the IGY surveyors calculated differed from their value by one meter out of 700 . Large systematic map errors are therefore no surprise and are thought to outweigh any random effects for this map.

Polychrome Glacier: The elevation profiles of this glacier were measured on the surface, and there were no intersections with bedrock contours. However, this glacier was the focus of the doctoral dissertation of the IGY map cartographer, and an extensive analysis of its quality was given there (Case, 1959). This map most likely meets the published accuracy of $\pm 2.5 \mathrm{~m}$. The apparent thickening near the steep terminus of this glacier (Fig. 5) could be due to small horizontal errors in either the map or our comparison with it. However, the thickening could also be real, caused by glacier flow into the area where the heavy debris cover has suppressed ablation.

McCall Glacier: The map shows major problems in the proglacial area (Table 3), and there are several dashed contours in the upper regions. Rabus and others (1995) studied the map problems and found them to be so significant that they preferred to use the 1956 USGS 1:63360 scale map to calculate the change in volume. We use their volume-change calculations for McCall Glacier in the next section. However, the elevation changes shown in Figure 5 were calculated with respect to the IGY map.

Worthington Glacier: This map was made from photographs of poor contrast that were taken when the glacier was snow-covered. There are many dashed contours. At first sight, the limited data also suggest a systematic error of $3 \mathrm{~m}$, but this is not significant, considering that there are only three bedrock intersections. The small standard error of the mean is probably an accident, judging from the values for other glaciers with more data. Nevertheless, we account for this possible shift and the dashed contours by increasing the respective systematic errors, as shown in Table 4.

Most of the error estimates in Table 4 are conservative. The random and systematic errors may be combined (assuming that they are independent) to give an estimate of the standard error in elevation at one of the contours. In most cases, the random error dominates and leads to an error of $\pm 5 \mathrm{~m}$ (8 $\mathrm{m}$ for Blue Glacier and $6 \mathrm{~m}$ for Worthington Glacier) in elevation. As discussed above, this is the error in HAE; height above mean sea level would depend on the accuracy of the geoid model used. The map errors shown in Table 4 are the limiting factor in the accuracy of our elevation-change calculations.

\section{VOLUME AND TERMINUS CHANGES}

\section{Calculation of volume change}

The problem of calculating glacier volume change by comparing sequential topographic maps is an old one (e.g. Finsterwalder, 1954). However, new methods are needed to compare maps with our elevation profiles, because a two-dimensional topographic map of the glacier must be constructed from profiles that consist of elevation vs position along only a few tracks down the glacier's surface. We have developed such a method of map construction that supplements the profile data with information from the IGY maps about the general shape of the glacier and of the surrounding valley.

First, an elevation change at each of the map contour elevations was determined. Some glaciers, such as Lemon Creek and Little Jarvis, are fairly simple, with only one main branch or tributary. On these we averaged the elevation change for the different profiles at each contour, with the results as shown in Figure 5. Other glaciers, such as Blue and Chikuminuk, have several major branches. On Blue Glacier we profiled most of these branches, and used the results of individual profiles within each branch. Below the confluence of these branches, we averaged the elevation changes from the different profiles. On other glaciers, such as West Gulkana, some smaller branches were not profiled at all. For those branches, we used profile data from the closest branch. In those cases where no profile data were collected at the highest elevations, the average of the uppermost data points was used (Fig. 5). Usually these highest areas are small and do not contribute significantly to the estimated volume change.

The resulting (average) elevation changes at each IGY contour were then used to construct new contours by a procedure similar to that described by Echelmeyer and others (1996). We assumed that during a change in elevation, each glacier contour retained its shape. Some justification for this assumption can be seen in detailed survey data from McCall Glacier (Rabus and others, 1995, fig. 5). Each contour was relabeled with the new elevation, and strained uniformly to fit between the new (1990s) glacier boundaries, which were found using the slopes of the valley walls as measured on the maps. The points of intersection of the new contours with the projected valley walls defined the new boundary of the glacier at the time of profiling. The procedure resulted in a new set of contours spaced at irregular elevation intervals. A set of contours corresponding to the elevation labels of the IGY map contours was then determined by interpolation. Map construction by this method was not feasible in the highest accumulation areas, but, where it was, Finsterwalder's (1954) method was used to compute the change in volume.

In the upper accumulation areas the slope of the valley walls was often difficult to determine, and the above procedure could not be used to find the new boundary, nor could the contours be strained. When this occurred, the boundaries were assumed to be unchanged from those mapped in the IGY. The volume change between each pair of contour lines in these regions was then calculated as the product of the area between these two contours and the mean elevation change for the pair. The total volume change for these regions was then found by summation. This was a reasonable approach because the elevation changes, and therefore 
the boundary changes, are generally small in these upper regions.

The resulting changes are summarized in Table 5 . The area-average thickness change is the total volume change divided by the average of the areas at the beginning and the end of the measurement interval. It is emphasized that the result depends upon our choice of glacier boundaries, shown in Figure 2a-i and discussed above. Seasonally corrected average thickness changes are also listed in Table 5. These corrections were necessary because the maps and elevation profiles were made at different times of year. Most of the IGY maps were produced from photographs taken in late summer, while most of the profiles were obtained early in the melt season. Corrections were usually made by subtracting the snow thicknesses in Table 2 from the average thickness changes, although a slightly more complex procedure had to be followed when the IGY photographs were made in mid-summer. Since there had usually been little if any ice ablation at the time of profiling, subtraction of the snow thickness at the time of profiling means, effectively, that the elevation change is calculated with respect to the previous summer surface, which occurred in late summer of the calendar year previous to that of profiling. Therefore, the time interval is reduced by a year except for McCall and Worthington Glaciers, for which no seasonal correction was necessary. The errors associated with seasonal corrections are not important over the long intervals (such as 1957 to the 1990s), but are important over the short intervals.
Because of the map problems discussed above, the values of the thickness change for Chikuminuk Glacier in Table 5 are those for the west branch only. The McCall Glacier data were taken from Rabus and Echelmeyer (in press) who used the 1956 USGS map, as noted above. We have also included volume-change calculations using the 1986 map of West Gulkana Glacier (Marcus and Reynolds, 1988), the 1989 map of Lemon Creek Glacier (Marcus and others, 1995), and various maps of Blue Glacier (Davey, 1962; USGS 1987 map); these results give some temporal information on the changes. Volume changes using the 1987 USGS map of Blue Glacier were calculated in a simplified and less accurate manner using the area distribution curve in Figure 6; no change in area was taken into account except near the terminus. The average elevation change was combined with the area distribution curve; individual branches were not treated separately.

The seasonally corrected thickness change of a glacier can be used to estimate the long-term average annual mass balance. In our convention, the annual balance is the mass balance averaged over the glacier surface. What we calculate is the long-term average of the annual balance, here abbreviated as "average annual balance", denoted $\left\langle b_{a}\right\rangle$; the brackets are used to emphasize the time averaging, which is usually over many years. Balance is expressed in $\mathrm{m} \mathrm{a}^{-1}$ (water equivalent). To obtain average balances from seasonally corrected average thickness changes we used a mean density of $850 \mathrm{~kg} \mathrm{~m}^{-3}$. As was discussed by Krimmel (1989),

Table 5. Glacier changes. The values in the last column are in water equivalent units. A negative change indicates mass loss from the time of mapping to the present

\begin{tabular}{|c|c|c|c|c|c|c|c|}
\hline \multirow[t]{2}{*}{ Glacier } & \multirow[t]{2}{*}{$\begin{array}{l}\text { Measurement dates and seasonally } \\
\text { corrected interval }{ }^{(1)}\end{array}$} & \multirow{2}{*}{$\begin{array}{l}\text { Volume change } \\
\qquad 10^{6} \mathrm{~m}^{3}\end{array}$} & \multirow{2}{*}{$\begin{array}{l}\text { Area at earlier } \\
\text { time } \\
10^{6} \mathrm{~m}^{2}\end{array}$} & \multirow{2}{*}{$\begin{array}{l}\text { Area at later time } \\
\qquad 10^{6} \mathrm{~m}^{2}\end{array}$} & \multirow{2}{*}{$\begin{array}{c}\text { Area-average } \\
\text { thickness change } \\
\mathrm{m}\end{array}$} & \multirow{2}{*}{$\begin{array}{c}\text { Seasonally corrected } \\
\text { average thickness } \\
\text { change } \\
\mathrm{m}\end{array}$} & \multirow{2}{*}{$\begin{array}{c}\text { Long-term average } \\
\text { mass balance }\left\langle b_{\mathrm{a}}\right\rangle \\
\qquad \mathrm{m} \mathrm{a}^{-1} \text { w.e. }\end{array}$} \\
\hline & & & & & & & \\
\hline Blue & $\begin{array}{l}1957-96(\mathrm{ss} / 57-\mathrm{ss} / 95) \\
1939-52(\mathrm{ss} / 39-\mathrm{ss} / 52) \\
1952-57(\mathrm{ss} / 52-\mathrm{ss} / 57) \\
1957-87^{(3)}(\mathrm{ss} / 57-\mathrm{ss} / 87) \\
1987-96^{(3)}(\mathrm{ss} / 87-\mathrm{ss} / 95)\end{array}$ & $\begin{array}{l}-5 \\
-31^{(2)} \\
+46^{(2)} \\
+30 \\
-24\end{array}$ & $\begin{array}{l}5.93 \\
5.73 \\
5.66 \\
5.93 \\
5.47\end{array}$ & $\begin{array}{l}5.93 \\
- \\
5.93 \\
5.47 \\
5.93\end{array}$ & $\begin{array}{r}-0.8 \\
-5.4 \\
+8.0 \\
+5.3 \\
-4.3\end{array}$ & $\begin{aligned}-5.8 & \pm 2.5 \\
-5.3 & \pm ? \\
7.7 & \pm 1.0 \\
4.4 & \pm 2.5 ? \\
-8.4 & \pm 2.5 ?\end{aligned}$ & $\begin{array}{l}-0.13 \pm 0.06 \\
-0.3 \pm ? \\
+1.3 \pm 0.2 \\
+0.1 \pm 0.1 ? \\
-0.9 \pm 0.3 ?\end{array}$ \\
\hline Bear Lake & $1957-94(\mathrm{ss} / 57-\mathrm{ss} / 93)$ & -65 & 6.77 & 6.68 & -9.7 & $-12.5 \pm 2.8$ & $-0.30 \pm 0.07$ \\
\hline Chikuminuk $^{(4)}$ & $1957-96(\mathrm{ss} / 57$ ss/95) & $(+8)$ & $(5.77)$ & $(5.33)$ & $(+1.4)$ & $(-3 \pm$ large $)$ & $(-0 \pm$ large $)$ \\
\hline Lemon Creek & $\begin{array}{l}1957-95(\mathrm{ss} / 57-\mathrm{ss} / 94) \\
1957-89(\mathrm{ss} / 57-\mathrm{ss} / 89) \\
1989-95(\mathrm{ss} / 89-\mathrm{ss} / 94)\end{array}$ & $\begin{array}{l}-164 \\
-132^{(5)} \\
-32^{6)}\end{array}$ & $\begin{array}{l}12.04 \\
12.62^{(5)} \\
-\end{array}$ & $\begin{array}{l}11.71 \\
11.73^{(5)}\end{array}$ & $\begin{array}{l}-13.8 \\
-10.8 \\
-3.0^{6}\end{array}$ & $\begin{array}{c}-15.8 \pm 2.5 \\
-11 \pm ? \\
-5 \pm ?\end{array}$ & $\begin{array}{c}-0.36 \pm 0.06 \\
-0.3 \pm ? \\
-0.8 \pm ?\end{array}$ \\
\hline Little Jarvis & $1957-95(\mathrm{ss} / 56-\mathrm{ss} / 94)$ & 0 & 2.50 & 2.45 & 0.0 & $-1.5 \pm 2.8$ & $-0.04 \pm 0.07$ \\
\hline $\mathrm{McCall}^{(7)}$ & $1956-93$ (ss/56-ss/93) & -64 & 6.20 & 6.00 & -10.5 & $-10.5 \pm 4.0$ & $-0.24 \pm 0.09$ \\
\hline Polychrome & $1957-95(\mathrm{ss} / 57-\mathrm{ss} / 94)$ & -15 & 1.84 & 1.70 & -8.5 & $-8.7 \pm 2.2$ & $-0.20 \pm 0.05$ \\
\hline West Gulkana & $\begin{array}{l}1957-93(\mathrm{ss} / 57-\mathrm{ss} / 92) \\
1957-86(\mathrm{ss} / 57-\mathrm{ss} / 86) \\
1986-93(\mathrm{ss} / 86-\mathrm{ss} / 92)\end{array}$ & $\begin{array}{l}-93 \\
-87 \\
-7\end{array}$ & $\begin{array}{l}4.20 \\
4.20 \\
3.65\end{array}$ & $\begin{array}{l}3.59 \\
3.65 \\
3.59\end{array}$ & $\begin{array}{l}-24.0 \\
-22 \\
-2\end{array}$ & $\begin{array}{c}-25.2 \pm 2.2 \\
-21 \pm ? \\
-4 \pm ?\end{array}$ & $\begin{array}{c}-0.61 \pm 0.06 \\
-0.6 \pm ? \\
-0.6 \pm ?\end{array}$ \\
\hline Worthington & $1957-94(5 / 57-5 / 94)$ & +5 & 8.55 & 8.32 & +0.6 & $+0.6 \pm 3.9$ & $+0.01 \pm 0.09$ \\
\hline
\end{tabular}

\footnotetext{
(1) Seasonally corrected measurement intervals are in parentheses; ss stands for "summer surface".

(2) From Davey (1962).

(3) Calculated using 1990 USGS 1:24000 Mount Olympus map, which was made from 1987 photographs.

(4) Chikuminuk vales are associated with large errors and should be used with caution.

(5) From Marcus and others (1995).

(6) Calculated by subtracting the two numbers above.

(7) From Rabus and Echelmeyer (in press) who used 1956 USGS map.
} 
the topographic method of mass-balance calculation does not account for the loss of old firn in the mid-elevation reaches of a glacier that is thinning. Sorge's law, prescribing a constant density profile through time, does not apply in this old-firn zone. In the ablation and upper accumulation zones we assumed a density of $900 \mathrm{~kg} \mathrm{~m}^{-3}$, and a value of 650 $\mathrm{kg} \mathrm{m}^{-3}$ for the old firn that was removed. The resulting mean density was obtained by weighting by the fractional area of each zone. Observations on two of the glaciers indicated that the fractional area was about 0.50 for the ablation zone where ice was melted, 0.20 for the old-firn zone and 0.30 for the accumulation zone. The estimated error in our mean density is about $6 \%$ in $\left\langle b_{a}\right\rangle$, which is small compared to the effect of error in the seasonally corrected thickness changes. The resulting average balances and the seasonally corrected averaging intervals are given in Table 5 .

In interpreting the elevation-change data, it is important to remember that the volume and average thickness changes of a glacier are determined by weighting the elevation change (Figs 4 and 5) by the area distribution function (Fig. 6). Little Jarvis Glacier is a good example of how this can affect the interpretation. Although thinning occurred along much of the glacier length (Fig. 5), the area-average thickness change (and thus $\left.\left\langle b_{\mathrm{a}}\right\rangle\right)$ was close to zero because of the large fractional area at higher elevations (Fig. 6), where thickening did occur.

\section{Terminus changes}

The IGY terminus positions were determined directly from the maps. The recent terminus positions of Bear Lake, Chikuminuk, McCall and Polychrome Glaciers were surveyed on the ground. The recent terminus positions of the other glaciers were determined from the profile data by identifying a distinct change in surface slope where the profile crossed the new terminus, sometimes aided by photographs taken at the time of the profiling. The results are summarized in Table 6. In most cases, the error in the average retreat rates is about $1 \mathrm{ma}^{-1}$, although it should be noted that the effects of seasonal changes in terminus position might increase this error somewhat. Most, but not all, of the glaciers retreated from their IGY positions. Data from several other maps have been included for comparison.

\section{ERRORS IN VOLUME GHANGE AND IN RELATED QUANTITIES}

It is convenient to discuss the errors in volume change in terms of the error in the area-average thickness change, which is simply the volume change divided by the average glacier area. There are three main sources of error. They arise from (1) errors in our construction of a glacier's surface from profile data; (2) random errors in elevation change (measured at the intersection of the profile track with the individual contours; Table 4); and (3) the corresponding systematic errors (also in Table 4).

Errors in map construction: A test of our algorithm for the construction of the new surface was conducted using the 1957 and 1986 West Gulkana Glacier maps (the latter from Marcus and Reynolds, 1988). Simulated ground tracks of airborne elevation profiles were drawn on the 1986 map, and contour-crossing elevations were determined. This permitted us to construct a version of the 1986 map using our algorithm. Then the volume and average thickness changes were computed between our

Table 6. Glacier terminus changes. Advance is taken as the recent position minus the IGY position along a line perpendicular to both terminus fronts. The last column $\left(f_{\mathrm{L}}\right)$ is the ratio of the length-averaged thickness change to that at the terminus

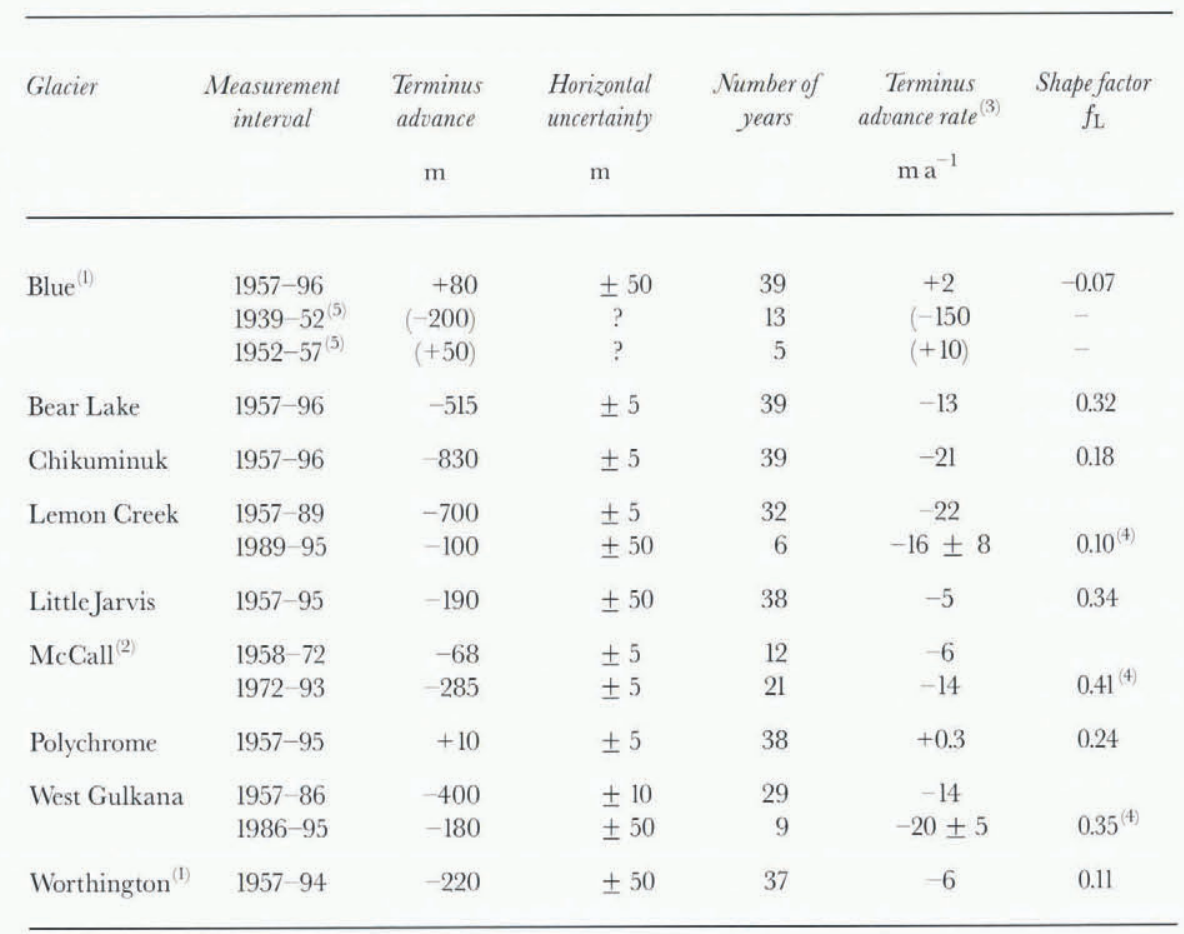

\footnotetext{
(I) There are two separate terminal lobes. The retreat rate shown is their mean advance rate.

(2) Values from Rabus and Echelmeyer (in press).

(3) Error in terminus advance rate is $\pm 1 \mathrm{~m} \mathrm{a}^{-1}$ except where noted.

(4) $f_{\mathrm{L}}$ was calculated over the entire measurement interval.

(5) From Davey (1962). Values are shown in parentheses because of unknown accuracy.
} 
"constructed" 1986 surface and the 1957 map. These changes were compared to those computed using Finsterwalder's method applied directly to the actual 1957 and 1986 maps. Taking the later values to be the "control", we found that the area-average thickness change calculated using the constructed surface was overestimated by $4.1 \mathrm{~m}$ on the lower part of the glacier and underestimated by $1.4 \mathrm{~m}$ on the upper. These differences on the lower and upper glacier tend to compensate because of the area distribution on this glacier; this may not always be the case. Over the entire glacier, our construction method gave an average thickness change of -20.9 compared to $-22.2 \mathrm{~m}$ for the direct map-to-map method, or an error of $1.3 \mathrm{~m}$ (Table 7). We use this error as representative of all glaciers.

Random errors in elevation change: Random errors of a few meters in elevation change at the individual contours (Table 4) should not have a large effect on the area-average thickness change, because their effects tend to cancel (Echelmeyer and others, 1996). Quantitatively, the error in the area-average thickness change due to these random errors is equal to the value in column 2 of Table 4 divided by the square root of the number of contours used to calculate the volume change. As this latter number is on the order of 100 for most glaciers, the random error component of the total error is quite small $(\sim 0.5 \mathrm{~m})$ This was confirmed on Worthington Glacier by using both the measured elevation curve in Figure 6 and a smoothed version of it. The difference in average thickness change was $0.5 \mathrm{~m}$.

Total error in average thickness change: The total error in the area-average thickness change is the combination of the map construction error (about $1.3 \mathrm{~m}$ ), the error resulting from random contour noise (typically $0.5 \mathrm{~m}$ ) and the systematic errors shown in Table 4 (and discussed above). These errors are independent, so the total error is the square root of the sum of their squares. The resulting total errors are mostly in the range $2-4 \mathrm{~m}$. The map errors tend to be the largest contributors to the total error in average thickness change, but the map construction error is significant.

Total error in seasonally corrected average thickness change: The error in the seasonally corrected average thickness change (Table 5) contains an additional, independent component, the error in the average snow depth at the time of profiling (Table 2). It is relatively small and increases the total error only slightly, at least over the long time intervals characteristic of the IGY-profile comparisons.

Total error in average annual balance: The total error in the long-term average annual balance (Table 5) contains yet another independent component, the error in the density of about $6 \%$. This is also relatively small, and the errors previously discussed dominate the total error.

The foregoing discussion is focused on the errors in the IGY-map-to-1990s-profile comparison, and the situation is slightly different over the shorter intervals in Table 5. For these intervals we have not analyzed the quality of the maps involved, and in the case of Blue Glacier we have used a less accurate method of map-to-map and map-to-profile comparison. We attempted error estimates when we had some
Table 7. Comparison of methods used to calculate volume change

\begin{tabular}{|c|c|c|c|}
\hline \multirow[t]{2}{*}{ Method } & $\begin{array}{l}\text { Lower region } \\
\qquad \Delta H^{(1)}\end{array}$ & $\begin{array}{c}\text { Upper region } \\
\Delta H^{1}\end{array}$ & $\begin{array}{c}\text { Entire glacier } \\
\qquad \Delta H^{(1)}\end{array}$ \\
\hline & $\mathrm{m}$ & $\mathrm{m}$ & $\mathrm{m}$ \\
\hline Direct map-to-map comparison ${ }^{(2)}$ & -47.6 & -12.9 & -22.2 \\
\hline Profile-to-map comparison ${ }^{3)}$ & -51.5 & -11.5 & -20.9 \\
\hline Difference between methods & +4.1 & -1.4 & -1.3 \\
\hline
\end{tabular}

(1) $\Delta H$ refers to area-average thickness change.

(2) $\Delta H$ calculated from direct comparison of two maps.

(3) $\Delta H$ calculated from comparison of one map with the surface constructed from profile data.

basis for estimating the quality of the relevant maps. It is clear that the errors are large over the shorter intervals. A particular problem is the lack of information about the quality of the 1989 Lemon Creek Glacier and 1986 West Gulkana Glacier maps (Marcus and Reynolds, 1988; Marcus and others, 1995); the photographs used for mapping seem to show relatively poor detail above the snowlines. Because of uncertainty in the boundaries used by Marcus and Reynolds for West Gulkana Glacier, we calculated the changes using our boundaries as shown in Figure $2 \mathrm{~h}$.

It is important to emphasize that the errors in Table 5 apply to glacier-wide average quantities. For example, the error in the seasonally corrected, glacier-wide average thickness change is considerably smaller than the errors in the elevation changes at individual contours discussed in an earlier section. These large individual errors are especially evident in Figure 5 for Blue and Little Jarvis Glaciers; in the former there is considerable scatter in elevation change, and in the latter there is a probably artificial step (at $1300 \mathrm{~m}$ ). Errors like these are mainly due to errors in individual contours. However, when glacier-wide averages are computed, the effect of such errors is reduced statistically, because they have a large random component. The most important error, and the most difficult to estimate, is that due to systematic bias in the contour lines.

\section{REGIONAL SUMMARY}

In this section, we review the glaciers in a regional perspective in order to illuminate any trends in volume or terminus change. For reference, the estimated long-term average annual mass balances (Table 5) are presented in the map in Figure 1. Also shown are the average values for Gulkana Glacier (personal communication from USGS, 1996; see also Echelmeyer and others, 1996) and Wolverine Glacier (personal communication from USGS, 1996) for the period 1966-95. The USGS average balances were obtained by averaging over the annual balances. The resulting error is unknown, but it could be larger than the typical errors in our map-to-profile comparisons, because of the cumulative effect of unknown systematic errors in the USGS annual balances.

\section{Brooks Range}

McCall Glacier, which is located in the Arctic climate regime of the Brooks Range, is the most northerly of the IGY glaciers. It has been the subject of intermittent study 
over the last four decades (Sater, 1959; Wendler and others, 1972; Rabus and others, 1995) and is part of an ongoing mass-balance study (Rabus, 1997; Rabus and Echelmeyer, in press). The terminus has retreated about $300 \mathrm{~m}$ and the average thickness has decreased by $11 \mathrm{~m}$. Rabus and Echelmeyer (in press) estimated average annual mass balances of -0.15 and $-0.33 \mathrm{~m} \mathrm{a}^{-1}$ for the periods $1958-72$ and $1972-93$, respectively. Thus, a doubling in the rate of mass loss has occurred. Their studies show that this glacier is representative of other glaciers in the northeastern Brooks Range, and of the region on a synoptic scale.

\section{Central Alaska}

The two glaciers located in this region are West Gulkana and Polychrome, in the eastern and western Alaska Range, respectively. Polychrome is not considered representative of its region, because it is heavily debris-covered for nearly half its length. The largest decrease in thickness occurred at $1700 \mathrm{~m}$ (Fig. 5), which was the lowest debris-free elevation on the glacier. Below this, the dense debris cover limited ablation.

Between 1957 and 1992 West Gulkana Glacier thinned by $25 \pm 2 \mathrm{~m}$. The larger Gulkana Glacier, located $4 \mathrm{~km}$ to the east, thinned by $11 \pm 5 \mathrm{~m}$ over a slightly longer interval (Echelmeyer and others, 1996; personal communication from USGS, 1996). The average annual mass balances were $-0.64 \pm 0.06$ and $-0.2 \pm 0.1 \mathrm{~m} \mathrm{a}^{-1}$ (water), respectively. Because the two glaciers have similar aspect and climate, it is likely that these impressive differences are due to differences in the distribution of glacier area with elevation. A large fraction of the area of West Gulkana Glacier is below $2000 \mathrm{~m}$, while a large fraction of Gulkana Glacier is higher. This elevation corresponds approximately to the present equilibrium-line altitude in this region (Mayo and Trabant, 1986).

Interpretation of temporal trends in the balance of West Gulkana Glacier from the data in Table 5 is difficult because of the uncertain errors involved, particularly over the interval 1986-93. Mayo and Trabant (1986) reported a positive change in the balance regime of Gulkana Glacier sometime around 1976. Such a trend is opposite that observed to the north on McCall Glacier. However, balances during the last 5 years have been strongly negative, which is similar to the recent trend on McCall Glacier (Rabus and Echelmeyer, in press).

Changes of other glaciers in central Alaska are discussed by Echelmeyer and others (1996).

\section{Bering Sea region}

Because of the problems with the map of Chikuminuk Glacier, our estimate of its thickness change is not reliable. The terminus retreat is more than $800 \mathrm{~m}$, the largest of all the nine glaciers. Given this retreat, it seems unlikely that Chikuminuk Glacier had many years of positive mass balance over the last four decades.

\section{Southern coastal Alaska}

Southern coastal Alaska is heavily glacierized, and no single glacier appears to be representative of it. The average annual balance varies from zero to about $-0.4 \mathrm{~m} \mathrm{a}^{-1}$ over relatively short distances (Fig. 1); there are no prominent eastwest trends.
The most westerly glacier, Bear Lake, is about $10 \mathrm{~km}$ from the ocean and has undergone a large decrease in average thickness $(-12.5 \pm 2.8 \mathrm{~m}$, seasonally corrected); this is close to that determined by Echelmeyer and others using USGS maps from 1950 to 1993 ( $-12 \pm 5 \mathrm{~m}$, seasonally corrected). Its average annual balance $\left(-0.30 \pm 0.07 \mathrm{~m} \mathrm{a}^{-1}\right)$ is not significantly different from that of Wolverine Glacier $\left(-0.25 \mathrm{~m} \mathrm{a}^{-1}\right.$; personal communication from USGS, 1996), located $35 \mathrm{~km}$ to the northwest and somewhat further inland, as measured from 1966 to 1995 . Wolverine, like Gulkana, could have significant errors in the long-term average balance arising from accumulating annual balances with a systematic error. Two hundred kilometers to the northeast and about $30 \mathrm{~km}$ from the ocean, Worthington Glacier showed little change (see also Echelmeyer and others, 1996). On the other side of the St Elias and Fairweather Mountains, Little Jarvis Glacier $(50 \mathrm{~km}$ from the coast) also showed little change. However, neither glacier is likely to represent accurately the changes in the heavily glacierized mountains that lie between them. The single IGY glacier in southeast Alaska, Lemon Creek, is located about $180 \mathrm{~km}$ south of Little Jarvis and $10 \mathrm{~km}$ from the coast. It has experienced the second largest average thickness change $(-16 \mathrm{~m})$ of the IGY glaciers. The data in Table 5 suggest a recent trend toward more negative recent balances, but the unknown errors make this conclusion uncertain. The rate of terminus retreat of Lemon Creek Glacier shows no significant trends (Table 6). The terminus is very steep.

\section{Washington}

Blue Glacier is located in a temperate maritime climate regime, about $65 \mathrm{~km}$ from the ocean, and it has a large mass-exchange rate. Several studies of its changes in surface elevation, mass balance and terminus position indicate a complex history (e.g. Davey, 1962; Echelmeyer, 1983; Armstrong, 1989; Spicer, 1989; McClung and Armstrong, 1993). The combined map and profile observations, expressed in terms of annual balance averaged over the different observational intervals, and terminus position referenced to 1957, are summarized in Figure 7. (As noted above, "Snow Dome" is included as part of the glacier.) This figure shows some of the detail that is not resolved by our long-term measurements. During the interval between the IGYand our profiling, $\left\langle b_{a}\right\rangle$ was negative, as shown by the heavy line, but there was a net advance of the terminus. Not shown in the figure is a retreat which began about 1980 .

Changes of several other glaciers in Washington have also been measured. The extensive mass-balance record of South Cascade Glacier indicates only a few positive balance years over the period 1959-95, with an average long-term annual balance of about $-0.5 \mathrm{~m} \mathrm{a}^{-1}$ over the entire period (Krimmel, 1995). This glacier is located about $200 \mathrm{~km}$ east of Blue Glacier in a drier, less maritime climate regime. Pelto (1996) also made observations on eight glaciers in the North Cascades from 1984 through 1994, and reported an average annual balance of $-0.38 \mathrm{~m} \mathrm{a}^{-1}$ for them. Since 1960 , South Cascade has retreated, with no short-term periods of advance. On the other hand, Harper (1993) observed that glaciers on Mount Baker advanced in the 1960s and 1970s.

\section{DISCUSSION}

It is worth recalling that our measurements give only the 


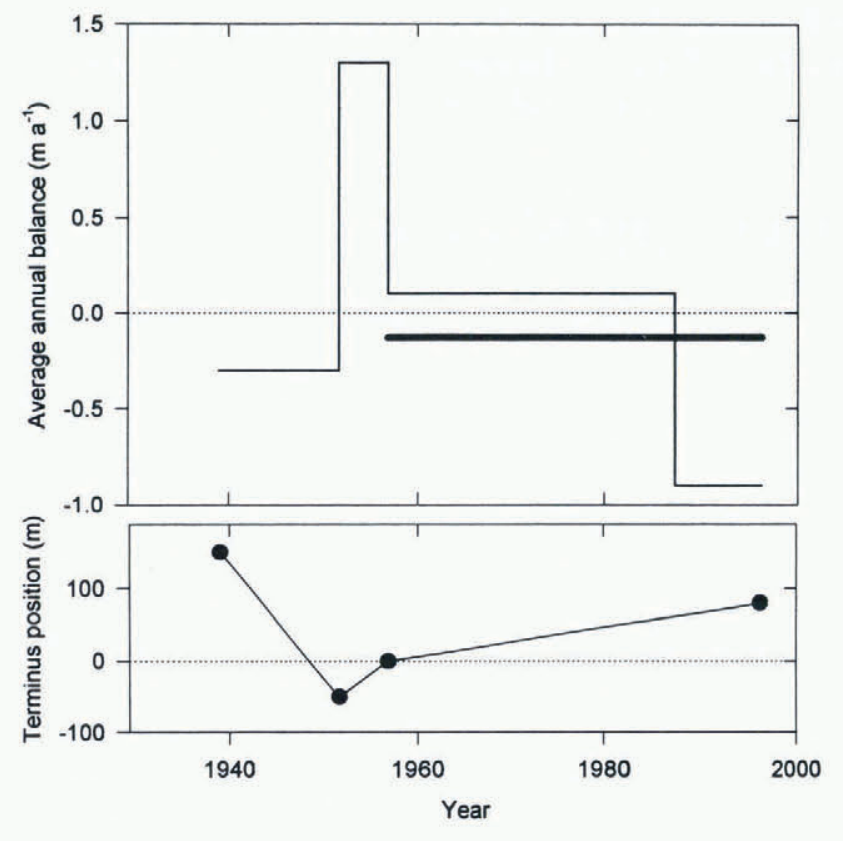

Fig. 7. Blue Glacier annual balance averaged over different time intervals, and its terminus position.

long-term (almost four-decade) average of the annual balance averaged over the glacier surface, and thus do not resolve what must be a complex temporal and spatial behavior; the temporal behavior was illustrated by Figure 7. One might argue that this long-term averaging might provide some simplification, and that this would facilitate the comparison of different glaciers to identify regional patterns, but these seem to be complex. There was a definite long-term thinning in Arctic and interior Alaska, but near the coast the trends are not as clear (Fig. 1). In this section we consider briefly some of the connections between the results and glacier geometry, climate, sea level and glacier dynamics.

\section{Glacier geometry}

Some of the complexity in the patterns of the changes of these glaciers must be because of their different geometries: size, surface slope, distribution of area with elevation and its relation to the position of the equilibrium line, and so on. It is clear that the distribution of area accounts for the different behavior of West Gulkana and Gulkana Glaciers noted above. However, the effects of geometry on the other glaciers is less obvious, and we have not attempted any systematic analysis.

\section{Changes in mass balance and climate}

Oerlemans and Fortuin (1992) have used an energy-balance model to investigate changes in a glacier's mass balance in response to a change in mean annual air temperature. Their model indicates that the temperature derivative of annual mass balance averaged over the surface of the glacier, here denoted by $b_{a}$, is dependent on the annual precipitation averaged over the glacier, $P$, following the empirical relation

$$
\frac{\partial b_{\mathrm{a}}}{\partial T}=-0.512-0.662 \log P
$$

for $P \geq 0.22 \mathrm{~m} \mathrm{a}^{-1}$. We have applied this relation to several of the glaciers in our study, recognizing that caution is in order because Equation (1) does not take two key factors into account, namely, the effects of glacier geometry and glacier flow; the latter causes most glaciers to adjust their sizes to attain zero annual mass balance after an extended climate change. An estimate of mean annual precipitation for the different glaciers was obtained from various sources; these sources and the estimates are listed in Table 8, along with $\partial b_{\mathrm{a}} / \partial T$ using Equation (1). If we assume that each glacier was in steady state (zero annual mass balance) at the start of the IGY, then we may use our values of the long-term average annual mass balance listed in Table 5 to estimate the effective temperature change, $\Delta T$, using Equation (1). If we also assume that the precipitation was constant at our estimated value over the approximately 38 year time period, and that the temperature change was a step change, without detailed temporal structure, then

$$
\Delta T \approx \frac{\left\langle b_{\mathrm{a}}\right\rangle}{\partial b_{\mathrm{a}} / \partial T} .
$$

These values of $\Delta T$ are given in Table 8 .

\section{Table 8. Estimated annual precipitation, the derivative of annual balance with respect to mean annual temperature, $\partial b_{\mathrm{a}} / \partial T$, and changes in mean annual air temperature, $\Delta T$, from Equation (1)}

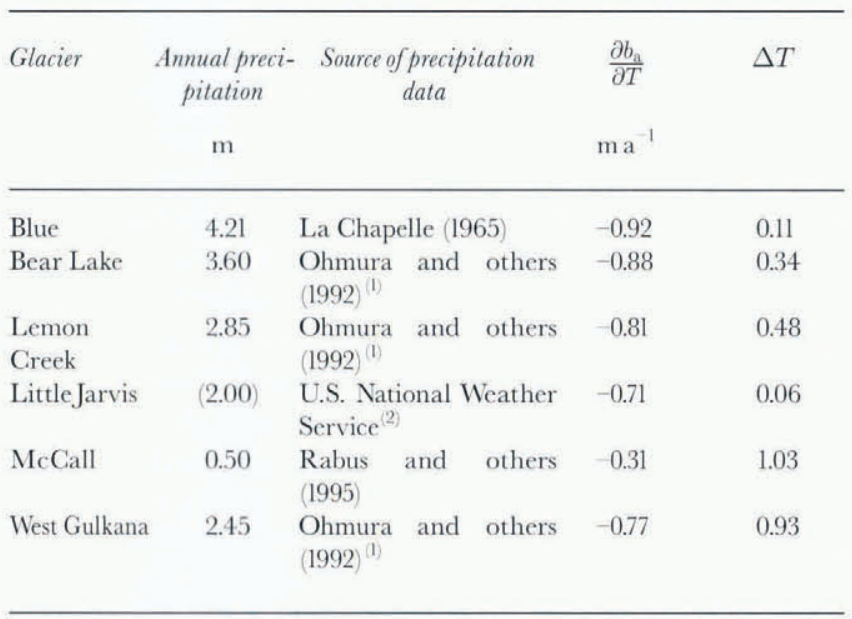

(1) Ohmura and others found total annual precipitation to be very close to the sum of the winter mass balance and the summer precipitation. These are the values reported here.

(2) Estimated from the $1.30 \mathrm{~m}$ average precipitation recorded for the interval 1961-90 in Haines, Alaska.

There are several assumptions leading to Equations (1) and (2) and they are probably weak. However, the values listed in Table 8 suggest that the temperature changes in Arctic and interior Alaska may have been larger than those in south coastal Alaska and coastal Washington. We could use the shorter-term balance changes listed in Table 5 for West Gulkana, Lemon Creek and Blue Glaciers to estimate temperature changes that are not tied to the assumption of zero initial balance. However, the shortcomings of Equation (1), the unusual geometry of the glaciers and the unknown accuracy of the 1980s maps make such an approach uncertain. Data of Rabus and Echelmeyer (in press) for McCall Glacier show a strong decrease in average annual mass balance from $1957-72\left(-0.15 \mathrm{~m} \mathrm{a}^{-1}\right)$ to $1972-93\left(-0.33 \mathrm{~m} \mathrm{a}^{-1}\right)$, and Oerlemans and Fortuin's model leads to an estimated $0.6 \mathrm{~K}$ temperature increase for this part of Alaska.

Although Equation (1) predicts a larger change in balance on a glacier with a large annual precipitation rate, the change in balance relative to a glacier's annual mass exchange (or glacier activity; Meier, 1984) is generally much 
larger on Arctic or sub-Arctic glaciers. For example, the average annual balance of Lemon Creek Glacier from 1957 to $1994\left(-0.36 \pm 0.06 \mathrm{~m} \mathrm{a}^{-1}\right)$ is somewhat more negative than that of McCall Glacier from 1956 to $1993(-0.24 \pm$ $0.09 \mathrm{~m} \mathrm{a}^{-1}$. However, the negative balance of McCall is the more impressive when compared with its winter accumulation, which it actually exceeds (Rabus and others, 1995). The negative Lemon Creek balance is only $10 \%$ of its winter accumulation.

\section{Sea level}

Because of the complexity of the pattern of glacier volume change, we have not attempted the sort of regional extrapolation that would be necessary for a direct calculation of the effect of glacier changes in western North America on sea level. However, the implications of our observations for an earlier extrapolation are of interest. In estimating the contribution of mountain glaciers to changing sea level, Meier (1984) extrapolated the limited glacier mass-balance data from around the world using an assumed regional relationship between the annual mass exchange of a glacier (onehalf of winter minus summer balance, or activity) and its mass balance. We checked this relationship using our average annual balances for the IGY glaciers and information on mass-exchange rates estimated by various methods, usually by extrapolation from other glaciers where it has been measured. Except for McCall Glacier, the ratios of average annual balance to activity are similar to those stated by Meier, but we find that a major problem with establishing this sort of relationship is the large uncertainties in the activities. The large negative average annual balance of McCall Glacier gave a value of -1.00 for the ratio, which is different than the -0.22 estimated by Meier. However, because of the limited glacierized area in the Brooks Range, this difference would have no effect on his estimate of sea-level change.

\section{Relation between volume and terminus position}

There is no simple connection between glacier volume and terminus position during the four-decade interval covered by our measurements. (A similar conclusion was reached by Echelmeyer and others, 1996). For example, the longterm volume changes of Worthington and Little Jarvis Glaciers were positive or near zero, but their termini retreated. The long-term volume change of Blue Glacier was negative and its terminus advanced; the advance is a clue to an earlier period of thickening. These observations indicate that there is a time lag between volume and terminus changes. This is no surprise, but it is of interest to consider how it fits into the present theoretical picture of glacier response. Nye (1960), Jóhannesson and others (1989) and Schwitter and Raymond (1993) have considered the possibility that the ratio of the thickness change averaged over the length of a glacier (without regard to changes in width) to the thickness change at the terminus, $f_{\mathrm{L}}$, is roughly constant, particularly over long time intervals. This ratio is important in the theory of the time response of a glacier to a change in balance, and one might hope that it would be reasonably constant when evaluated for the long; almost 40 year interval of our measurements. For the nine IGY glaciers, the ratio varies considerably, as shown in the last column in Table 6 ; the mean is 0.24 and the standard deviation about the mean is 0.13 . Since glacier width is rarely uniform, another ratio was calculated by replacing the longitudinal average by the surface average (the average thickness change). The scatter was not reduced, indicating that other factors are involved.

\section{SUMMARY AND CONCLUSIONS}

As part of the IGY program (1957-58), nine glaciers were chosen to represent different climatic regimes in North America, and maps were made of them using aerial photogrammetry. We measured surface-elevation profiles of these glaciers during the period 1993-96, most with an airborne profiling system. The original maps and the new profiles were transformed into the same geodetic datum by resurveying the IGY control. By comparing these profiles with the maps, we then determined volume and area-average thickness changes for each glacier. We also measured changes in terminus position. Errors in the volume-change calculations were dominated by errors in the maps, especially those with poor photographic control or contrast, although the error associated with map construction from a limited number of profiles was significant.

All glaciers showed significant thinning at lower elevations. At higher elevations some glaciers thinned and others thickened, but the magnitude of the changes was much less than at lower elevations. The area-average thickness changes and the long-term average annual mass balances were negative for all but two glaciers, which had near-zero changes. For the eight glaciers for which we could obtain quantitative information, the mean thickness change was $-10 \mathrm{~m}$ with a large scatter, $8 \mathrm{~m}$ standard deviation. The long-term average thickness changes did not show simple regional trends. Most of the glaciers retreated over the $\sim 38$ year time period, but one showed significant advance. No consistent relationship between volume and terminus changes was identified.

It remains to be discussed how representative the nine IGY glaciers are of the glacierized regions they were chosen to represent. Clearly, Polychrome Glacier, which has an extensive debris cover, is not representative of the central Alaska Range. West Gulkana Glacier, also in the Alaska Range, showed a large decrease in thickness compared with that of Gulkana Glacier a few kilometers away (Echelmeyer and others, 1996; personal communication from USGS, 1996). As noted above, this is due to the area-elevation distribution of West Gulkana Glacier, which at least on the basis of casual observation is unlikely to be representative of the glaciers in this part of Alaska. In the Bering Sea region, the map of Chikuminuk Glacier has such large errors that it is not of much use. The IGY map of McCall Glacier also has large errors, but a USGS map has been analyzed (Rabus, 1997). Rabus and Echelmeyer (in press) found McCall to be representative of the glaciers in the northeastern Brooks Range. Bear Lake, Worthington, Lemon Creek and Blue Glaciers are thought to represent the regions in which they are located. However, the heavily glacierized St Elias and Fairweather Mountains are probably not well represented by either Worthington or Little Jarvis Glacier, as these two are located on the periphery of the ranges.

On a broader view, the fact that most of the nine IGY glaciers have thinned over the study period does support the observation that, in general, North American glaciers are thinning. However, our study shows that the IGY glaciers are not sufficient to resolve the regional trends in 
balance. What coverage would be needed to resolve the regional trends is an important question that has not been answered by our study, but perhaps may be answered in the future with the help of the accurate and efficient methods of airborne elevation profiling.

\section{ACKNOWLEDGEMENTS}

We wish to thank E. Mann, C. Larsen, B. Rabus and H. Conway for help in the field, and J. Gorda and L. Sombardier for help with preparing the figures. The IGY photography and field notes were kindly supplied by J. Case and $\mathrm{H}$. Brecher. K. Abnett and B. Rabus provided several of the programs used in data collection and analysis. J. Mitchell answered many questions regarding survey control and photogrammetry. We were fortunate to have penetrating comments on the manuscript from A. Post, M. Sturm, M. Pelto and two anonymous reviewers. The work was supported by NASA grant NAGW3727.

\section{REFERENGES}

American Geographical Society. 1960. Nine glacier maps, northwestern . North America. New York, American Geographical Society. (AGS Special Publication 34.

Armstrong, R. L. 1989. Mass balance history of Blue Glacier, Washington, U.S.A. In Oerlemans, J., ed. Glacier fluctuations and climatic change. Dordrecht, etc., Kluwer Academic Publishers, 183- 192.

Case, J. B. 1959. A comparison of photogrammetric methods in glacier mapping. (Ph.D. thesis, Ohio State University.)

Davey, H. 1962. Changes in Blue Glacier, Mt. Olympus, Washington. Columbus, $\mathrm{OH}$, Ohio State University Resource Foundation for American Geographical Society, Project 1278. (Report 1.)

Echelmeyer, K. A. 1983. Response of Blue Glacier to a perturbation in ice thickness: theory and observations. (Ph.D. thesis, California Institute of Technology.

Echelmeyer, K. A. and 8 others. 1996. Airborne surface profiling of glaciers: a case-study in Alaska. f. Glaciol., 42 (142), 538-547.

Finsterwalder, R. 1954. Photogrammetry and glacier research with special reference to glacier retreat in the eastern Alps. F. Glaciol., 2 (15), 306-315.

Haeberli, W. and M. Hoelzle. eds. 1993. Fluctuations of glaciers 1985-1990 (Vol. VI). Wallingford, Oxon, IAHS Press; Nairobi, UNEP; Paris, Unesco.

Harper, J. T. 1993. Glacier terminus fluctuations on Mount Baker, Washington, U.S.A., 1940-1990, and climatic variations. Arct. Alp. Res., 25 (4), $332-340$.

Jóhannesson, T., C. Raymond and E. D. Waddington. 1989. Time-scale for adjustment of glaciers to changes in mass balance. $f$. Glaciol., 35(121), $355-369$.

Krimmel, R. M. 1989. Mass balance and volume of South Cascade Glacier, Washington, 1958-1985. In Oerlemans, J., ed. Glacier fluctuations and climatic change. Dordrecht, etc., Kluwer Academic Publishers, 193-206.

Krimmel, R. M. 1995. Water, ice, and meteorological measurements at South Cascade Glacier, Washington, 1994 balance year. U.S. Geol. Surv. Water-Resour. Invest. Rep. 95-4162.

LaChapelle, E. 1965. The mass budget of Blue Glacier, Washington. f. Glaciol., 5(41), $609-623$.

March, R. S. and D. C. Trabant. 1996. Mass balance, meteorological, ice motion, surface altitude, and runoff data at Gulkana Glacier, Alaska, 1992 balance year. U.S. Geol. Surv. Water-Resour. Invest. Rep. 95-4277.

Marcus, M. G. and W. J. Reynolds, eds. 1988. Glacier and climate studies, West Gulkana Glacier and environs, Alaska. West Point, NY, U.S. Military Academy. (Res. Pap. 1) and Tempe, AZ, Arizona State University. Department of Geography. (Publ. Ser. 4.)

Marcus, M. G., F. B. Chambers, M. M. Miller and M. Lang. 1995. Recent trends in the Lemon Creek Glacier, Alaska. Phys. Geogr., 16 (2), 150-161.

Mayo, L. R. and D. C. Trabant. 1986. Recent growth of Gulkana Glacier, Alaska Range, and its relation to glacier-fed river runoff, U.S. Geol. Surv. Water-Supply Pap. 2290, 91-99.

McClung, D. M. and R. L. Armstrong. 1993. Temperate glacier time response from field data. J. Glaciol., 39 (132), 323-326.

Meier, M. F. 1984. Contribution of small glaciers to global sea level. Science, 226 (4681), $1418-1421$.

Meier, M. F. 1990. Reduced rise in sea level. Nature, 343 6254), 115-116.

Nye, J. F. 1960. The response of glaciers and ice-sheets to seasonal and climatic changes. Proc. R. Soc, London, Ser. A, 256(1287), 559-584.

Oerlemans, J. and J. P. F. Fortuin. 1992. Sensitivity of glaciers and small ice caps to greenhouse warming. Science, 258(5079), 115-117.

Ohmura, A., P. Kasser and M. Funk. 1992. Climate at the equilibrium line of glaciers. 7. Glaciol., 38(130), 397-411.

Pelto, M. S. 1996. Annual net balance of North Cascade glaciers, 1984-94. j. Glaciol., $42(140), 3-9$.

Rabus, B. 1997. The flow and mass balance of McCall Glacier, northeastern Brooks Range, Alaska. (Ph.D. thesis, University of Alaska, Fairbanks.)

Rabus, B.T. and K. A. Echelmeyer. In press. The mass balance of McCall Glacier, Brooks Range, Alaska: its regional relevance and implications for the climate change in the Arctic. f. Glaciol.

Rabus, B., K. Echelmeyer, D. Trabant and C. Benson. 1995. Recent changes of McCall Glacier, Alaska. Ann. Glaciol., 21, 231-239.

Sapiano, J.J. 1996. Elevation, volume and terminus changes of nine glaciers in North America. (M.Sc. thesis, University of Alaska, Fairbanks.)

Sater, J. E. 1959. Glacier studies of the McCall Glacier, Alaska. Arctic, 12 (2), $82-86$.

Schwitter, M. P. and C. F. Raymond. 1993. Changes in the longitudinal profiles of glaciers during advance and retreat. f. Glaciol., 39 (133), 582-590.

Spicer, R. C. 1989. Recent variations of Blue Glacier, Olympic Mountains, Washington, U.S.A. Arct. Alp. Res., 21 (1), 1-21.

Wendler, G., C. Fahl and S. Corbin. 1972. Mass balance studies on the McCall Glacier, Brooks Range, Alaska. Arct. Alp. Res., 4(3), 211-222.

MS received 21 April 1997 and accepted in revised form 17 November 1997 